\title{
Assessment of Student Learning Attitudes toward CDIO-Based Course Design: A Case Study in Taiwan
}

\author{
Bor-Tyng Wang, Ching-Yi Lee, Chuang-Chien Chiu, and Chun-Wen Teng
}

\begin{abstract}
The purpose of this study is to investigate the application of "Conceive-Design-Implement-Operate" (CDIO) approach in the construction and engineering colleges in a private university in central Taiwan. The study wants to investigate students' creative thinking ability, problem-solving ability and their attitudes toward this "learning by doing" method. Students from the construction and engineering colleges were chosen to form interdisciplinary teams, and took interdisciplinary required courses, which are aimed to help students discover questions and find solutions through the process of stimulating students' imagination. After the courses, a 32-item questionnaire on a Likert scale was given to 150 students in both colleges to measure their learning attitude toward the CDIO-based courses. The results showed that students are more engaged and motivated in the courses, and they learn how to integrate feedback from their peers. Overall, students have positive attitudes toward the CDIO-based program and they are willing to take more relevant courses in the future.
\end{abstract}

Index Terms-CDIO, creative thinking, learning attitude.

\section{INTRODUCTION}

The approach of Conceive-Design-Implement-Operate (CDIO) is a new model for improving engineering education because the higher education is facing the problems of low academic achievement among students [1]. How to motivate the students to learn has become a big problem [2]. Thus, the CDIO approach provides an opportunity for students to solve problems, complete projects and learn new concepts in thinking through hands-on practices and cooperate with their peers [3].

Hence, the private university in central Taiwan sensed this crisis and wanted to make a change. The school applied the CDIO approach in the construction and engineering colleges. A total of 150 students from both colleges took the CDIO-based courses. They took the required courses of introduction to embedded system, practice of bim-ecotect analysis, and applications on geospatial information in the spring semester, 2016. In these courses, students were encouraged to form interdisciplinary teams, and teachers assigned tasks to them. In addition, Students had to work

Manuscript received November 21, 2016; revised January 23, 2017. This work was supported by the Ministry of Science and Technology of Taiwan under Grant No. 104-2511-S-035 -003 -MY3

B. T. Wang is with the Foreign Language Center, Feng-Chia University, Taiwan (e-mail: btwang.tw@gmail.com).

C. Y. Lee is with the Center for Teaching and Learning Resource, Feng-Chia University, Taiwan (e-mail: cyilee@fcu.edu.tw).

C. C. Chiu is with Feng-Chia University, Taiwan (e-mail: chiuc@fcu.edu.tw).

C. W. Teng is with Graduate Institute of Public Policy, Feng-Chia University, Taiwan (e-mail: cwteng@fcu.edu.tw). together to solve the problems, and they were also encouraged to think of new ideas. In these courses, they are "student-centered" instead of only paying attention to teacher's guidance. In order to check students' learning attitudes toward the CDIO-based program, a 32-item questionnaire on a Likert scale was given to 150 students in both colleges. In the past, there are some creative problem-solving scales; however, there is no CDIO-based creative problem-solving scale. By applying the CDIO approach, the research team wants to inspire college students' imagination and encourage them to find problems and solutions. So the team developed the "CDIO-based creative problem-solving scale" to evaluate students' attitudes toward the course design.

Therefore, the research question of this paper can be summarized as follows:

1) How do students feel about the CDIO-based courses?

2) Do students' problem-solving ability increase after taking the CDIO-based courses?

\section{LITERATURE REVIEW}

In this section, the CDIO approach, imagination and innovation, and problem-solving ability are introduced.

\section{A. $C D I O$}

In the late 1990s, a group of educators of engineering field noticed that the engineers need not only professional backgrounds but also other abilities to solve problems we faced nowadays [4]. In order to solve the problem, a new International engineering education model, Conceive-Design-Implement-Operate (CDIO), was proposed by MIT and the Royal Swedish Academy of Sciences in 2000 [5]. The basic idea of CDIO is that under the premises of maintaining scientific basis, the courses should strengthen the engineering practices and develop the engineering abilities [5]. The aims of CDIO hope graduates from engineering field possess abilities to imagine, design, practice, and operate the complex engineering systems in the group-based environment in society nowadays [5].

There twelve standards, which systematically covers the main requirements of Engineering Education of CDIO [5]-[7]. The twelve standards can be divided into five main domains: curriculum, teaching and learning methods, assessment, faculty competence, and workspace [5]-[7]. Moreover, the central idea of CDIO is to lead the engineering educators to meet the demands of Engineering Education depend on the resources in different situations [5]. The following are the important features of CDIO in Engineering Education [5]-[7]: 


\section{1) Build up the view of product orientation}

Try to understand students' values by the products they designed in CDIO courses. Students can improve their human interactions, knowledge, and technical skills through modifying and improving their products. As a result, the students we cultivated will be the talents who really possess knowledge of Engineering and practical abilities.

\section{2) Encourage students to attend teaching practices}

CDIO engineering education model helps cultivate students' study habits because its process emphasizes on their group values, cognition to their products, and individual learning attitude. Under limited Engineering Education resources, students can get considerable effectiveness by the comprehensive utilization of resources. They can manufacture products at school immediately instead of waiting until they enter the workforce. Moreover, imagination evoked during the class will form a new teaching situation and atmosphere.

\section{3) Build up students' confidences}

The educational idea of CDIO is to improve students' learning abilities by teachers' raising expectations to them. Students discover their potentials in the product development process and create unlimited possibility by changing their learning attitude in CDIO courses.

\section{4) Globalization}

Promoting CDIO engineering education model is conducive to the connections between students or schools and the world. It provides students with the most straightforward learning opportunities.

\section{B. Imagination and Innovation}

Imagination is the way of developing effective action, cultivating the innovative problem-solving ability, and finally forming a sense of community ability [8]. Albert Einstein once said that "Imagination is more important than knowledge. For knowledge is limited, whereas imagination embraces the entire world, stimulating progress, giving birth to evolution. It is, strictly speaking, a real factor in scientific research." No imagination, no insight ability, not to mention the problem-solving and the motion of research and innovation [9]. Innovation is not brought about by accident, but by the result of a series of events. According to Gardner (2007), students will be able to solve problems and adapt the changing world only if they have creative thinking skills [9]. Consequently, we can sum up that imagination is the way of developing effective action, cultivating the innovative problem-solving ability, and finally forming a sense of community ability [9], [10].

In addition, students should make use of design thinking to solve problems and create new values [11]-[13]. The design thinking courses of Institute of Design at Stanford emphasis on five stages: Empathize, Define, Ideate, Prototype, and Test [12]. In addition, the idea of the Tech Museum of Innovation is exploration and innovation, which contain human care at the same time. Therefore, we can find out that it is a progressive process from imagination to innovation [14], [15]. This process should keep brainstorming for extending out more ideas to discover problems and solutions of them.
In addition, the operation course of imagination can be induced by cross-field. Imagination contains the following rules [14], [15]. 1) Turn extensive life experiences into different elements to find out new ideas. 2) Imagination helps people develop simulation capability. 3) The connection between sentiment and pictures can motivate the audiences. 4) Finally, people can create the real exited objects. Thus, we can classify four steps of the process from imagination to innovation. First, we need to discover the problem and classify it by whether it needs solving or improving. Then gather interdisciplinary talents to put their ideas of solving the problem. They can give many different thoughts to enhance the chances of solving problems. Furthermore, we can go to the next stage, prototype design, which visualizes our thoughts. After continuously amending and improving the design, we finally get the model. Finally, test and amend the product again and again at the implementation phase. Thus it can be seen that it is important to create a learning environment for people have different backgrounds to exchange their ideas and design thinking [12].

Moreover, imagination provides learning motivations [16]. Students' learning motivations are affected by the course contents, teacher characteristics and students' individual different [17]. The learning motivations can divide into extrinsic motivation and intrinsic motivation [18], [19]. The encouragements from teachers and rewards belong to extrinsic motivation. On the other hand, the intrinsic motivation attracts the students' interests and makes them be willing to make efforts to learn something. Therefore, motivate students' intrinsic learning motivations will help enhance their willingness to learn effectively [18], [19]. Induce students' imagination can stimulate their intrinsic motivations. Evoking imagination can stimulate students' intrinsic learning motivations. Teachers create the opportunities to interact with students, discover the problems, and solve the problems so that the students can apply knowledge practically, and discuss with each other, giving positive and innovative feedbacks, and finally create a fine product.

Finally, imagination makes people help the unpredictable future. The world is changeable, and people cannot precisely predict how it will be. Imagination helps us training our multi-thinking ability. Imagination developed by learners may become the ability of developing creativity, so it is the power of evoking creativity. The skills of imagining can be acquired through learning. Based on the above information, we know that creativity stimulate our abilities of innovating and capabilities of facing the challenges in the future [8]-[10].

\section{Problem-Solving Ability}

Problem-solving ability helps students discover the problems, collect data, and analysis them with experiences and knowledge that they already know [20]. Then they can get new approaches of solve the problems after exploring and reasoning. It is a performance of higher order cognition that Gagné treats problem-solving as a way of learning at a learner's perspective [21]. This kind of performance can help learners generate new observations and restructure their thinking course. Thus, problem-solving is not only a learning 
method but also a higher order cognitive ability. The results after solving the problems should be meaningful, that is, it should meet all the learners' demands of learning [21].

Studies have showed that students' problem-solving abilities would be affected by their attitudes, thinking styles, emotional intelligences, the socioeconomic status of their families, etc [21]. Under all circumstances, one of the core purposes of public education is to let students understand how to collect and categorize data, and make initial analysis and decision by critical thinking through various learning activities. Then reach to an agreement on using relevant information to effectively solve issues by communicating and negotiating rationally with others.

The process of solving problems varies from person to person and it can be summed up as follows [20], [21]:

1) Discover problems.

2) Define or describe the problems.

3) Develop problem-solving strategies.

4) Start the problem-solving process.

5) Check the result after solving the problems.

\section{RESEARCH DESIGN}

\section{A. Participants}

A total of 150 students in the construction and engineering colleges in a private university in central Taiwan joined the CDIO-based courses. They took the required courses of introduction to embedded system, practice of bim-ecotect analysis, and applications on geospatial information in the spring semester, 2016. After the courses, they are asked to fill out the questionnaire, called "CDIO-based creative problem-solving scale," to collect their feedback toward the CDIO-based courses.

In this study, $86 \%$ of the participants are males and $16 \%$ are females. Most of them are sophomore and junior students (79\%).

\section{B. Research Tool}

In this study, the research tool is the five-point Likert scale consisting of 32 items and one open-ended question. Students respond to each item on a 1 to 5 Likert scale, with 5 being high. The scale is developed by a team of experts, and it is developed to investigate students' creative thinking ability (items 1-7), problem-solving ability (items 8-23) and their attitudes toward the CDIO-based courses (items 24-32). Therefore, it is called "CDIO-based creative problem-solving scale." The options are "strongly disagree, disagree, can't decide, agree and strongly agree." Students need to choose the option that best reflects their opinions. Moreover, there are 29 positive statements and 3 negative statements in the scale.

First, KMO values are tested to check if the items are adequate. In this study, the KMO values reach 0.8 $(p=.000<.001)$; hence, the samples are adequate. The results are shown in Table I.

TABLE I: KMO AND BARTLETT TEST

\begin{tabular}{llll}
\hline \hline Items & KMO & Bartlett & P value \\
\hline Items $1 \sim 32$ & .857 & 1346.082 & .000 \\
\hline \hline
\end{tabular}

In addition, the Cronbach's alpha of the scale is above 0.8 (Cronbach's alpha $=.881$ ), which shows the measure of internal consistency of the scale (reliability). Also, before the questionnaire was issued, the questionnaire was adjusted by expert examination, so the questionnaires have content validity.

\section{RESUlTS AND DisCUSSIONS}

In this section, the results of the CDIO-based creative problem-solving scale, including students' creative thinking ability, problem-solving ability and their attitudes toward CDIO-based courses, are introduced.

\section{A. Students' Creative Thinking Ability}

The mean scores of students' creative thinking ability are summarized in Table II. Overall, students strongly agree with item 7, which presents their confidence in integrating ideas to solve problems. Item 2 "I use a risk-based approach to solve the problem" ranks the lowest among the scale items. It's probably because of the term "risk-based" scares some of the students. However, the averages of items 1, 3, 4 and 6 are around 3.8, which means students' thinking ability has been inspired to be applied to the projects.

TABLE II: THE STUDENTS' CREATIVE THINKING ABILITY

\begin{tabular}{lll}
\hline \hline Items & $M$ & $S D$ \\
\hline $\begin{array}{l}\text { 1. I can come up with creating brand new solutions or } \\
\text { ideas. }\end{array}$ & 3.82 & 0.59 \\
$\begin{array}{l}\text { 2. I use a risk-based approach to solve the problem. } \\
\text { 3. I always carefully think about new technology or }\end{array}$ & 3.53 & 0.65 \\
$\quad 3.87$ & 0.71 \\
$\quad$ concepts before accepting them. & 3.85 & 0.68 \\
$\begin{array}{l}\text { 4. I can develop logical plans to solve problems. } \\
\text { 5. I can integrate substitutional opinions. }\end{array}$ & 3.94 & 0.57 \\
$\begin{array}{l}\text { 6. I can create interdisciplinary knowledge. } \\
\text { 7. I can integrate ideas and elaborate patterns to solve } \\
\text { problems. }\end{array}$ & 3.82 & 0.72 \\
\hline \hline
\end{tabular}

\section{B. Students' Problem-Solving Ability}

The mean scores, and standard errors of the students' problem-solving scale are listed in Table III. According to the results, item 20 and item 22 rank the top two in the scale, respectively. This shows students enjoying working and learning with peers and they also find the whole process exciting. They are willing to speak out and express their ideas while working in a team. They also show positive attitudes toward problem-solving. In this scale, item 23 is a negative statement, which scores 2.22 . Hence, we can assume that students do not take the process of problem-solving as a waste of time. On the contrary, they believe there is an answer to every problem, and they identify possible ways to solve the problem (items 8, 10, and 11). Moreover, the students enjoy the process of problem-solving and they find it interesting and exciting (items 18 and 20).

\section{Students'Attitude toward CDIO-based Courses}

In terms of students' attitude toward CDIO-based courses (items 24-32), the descriptive statistical analysis report is presented in Table IV.

The top three items in the questionnaire are item 26, item 25 and item 28, respectively. Item 26 aims to test students' 
ability to respect different opinions and ideas while item 25 and item 28 verify students' problem-solving ability has increased through the CDIO-based curriculum. Item 32 "I like this course, and I don't feel tired even when I spend a lot of time on it" gets the lowest score. The reason may be that comparing to other subjects, CDIO emphasizes "Learning by doing." Hence, students may spend more time and energy on completing the projects.

TABLE III: THE STUDENTS’ PROBLEM-SOLVING ABILITY

\begin{tabular}{|c|c|c|}
\hline Items & $M$ & $S D$ \\
\hline $\begin{array}{l}\text { 8. I try to find out solutions which can't be taught in the } \\
\text { classroom. }\end{array}$ & 4.01 & 0.52 \\
\hline $\begin{array}{l}\text { 9. I think that only people without question will ask } \\
\text { questions. }\end{array}$ & 2.07 & 1.03 \\
\hline $\begin{array}{l}\text { 10. When I notice confusing things in the daily life, I will } \\
\text { find answers. }\end{array}$ & 3.70 & 0.61 \\
\hline 11. I believe every problem has a solution. & 3.71 & 0.84 \\
\hline $\begin{array}{l}\text { 12. I can use all relative factors as evidence to construct a } \\
\text { clear insight of the problem state. }\end{array}$ & 3.83 & 0.55 \\
\hline $\begin{array}{l}\text { 13. I can identify multiple ways to solve problems with } \\
\text { specific preconditions. }\end{array}$ & 3.84 & 0.56 \\
\hline 14. I can propose one or more solutions. & 3.87 & 0.57 \\
\hline 15. I can infer or diagnose the feasibility of solutions. & 3.92 & 0.56 \\
\hline $\begin{array}{l}\text { 16. I can examine the impacts brought upon by the } \\
\text { solutions. }\end{array}$ & 3.73 & 0.62 \\
\hline 17. I can practice different solutions. & 3.71 & 0.59 \\
\hline 18. I find solving problems interesting. & 4.08 & 0.62 \\
\hline $\begin{array}{l}\text { 19. Only when I have the confidence of success, I will } \\
\text { solve problems. }\end{array}$ & 3.43 & 0.92 \\
\hline 20. I find the process of coming up with a solution exciting. & 4.11 & 0.62 \\
\hline $\begin{array}{l}\text { 21. While solving problems, I'm not afraid to be ridiculed } \\
\text { when making mistakes }\end{array}$ & 3.87 & 0.65 \\
\hline $\begin{array}{l}\text { 22. I enjoy exchanging others' opinions and absorbing } \\
\text { them }\end{array}$ & 4.10 & 0.57 \\
\hline 23. I think that challenging questions is a waste of time & 2.22 & 1.01 \\
\hline
\end{tabular}

TABLE IV: THE STUDENTS’ ATTITUDE TOWARD CDIO-BASED COURSES

\begin{tabular}{llc}
\hline \hline Items & $M$ & $S D$ \\
\hline $\begin{array}{l}\text { 24. I find the teacher's course design making me think } \\
\text { keen. }\end{array}$ & 3.91 & 0.60 \\
$\begin{array}{l}\text { 25. I understand that there are different approaches to solve } \\
\text { problems. }\end{array}$ & 4.04 & 0.49 \\
$\begin{array}{l}\text { 26. I respect different ideas and opinions. } \\
\text { 27. I acquire professional skills through implementation. }\end{array}$ & 4.19 & 0.60 \\
$\begin{array}{l}\text { 28. This course can approve my problem solving abilities. } \\
\text { 29. I think implementation courses as a waste of time. }\end{array}$ & 4.04 & 0.65 \\
$\begin{array}{l}\text { 30. I think taking courses like this can contribute to my } \\
\text { future employment. }\end{array}$ & 3.94 & 0.50 \\
$\begin{array}{l}\text { 31. I will do my best to complete projects to view my } \\
\text { achievements. }\end{array}$ & 4.03 & 0.60 \\
32. I like this course, and I don't feel tired even when I & 3.65 & 0.74 \\
$\quad$ spend a lot of time on it. & & \\
\hline \hline
\end{tabular}

\section{Open-Ended Question Discussion}

In the "CDIO-based creative problem-solving scale," item 33 is an open-ended question which ask students: In the future, what kind of courses do you expect the school to provide? The feedback from the students can be summarized as follows:

1) Students want more hands-on activities.

$S$ : project-oriented courses, learning by doing courses

S: APP software implementation

2) Students expect more interdisciplinary cooperation.

$S$ : similar courses can be done in a way that takes advantage of teamwork and in conjunction with the course content taught during this semester, which can train our ability to work with others and apply what we have learned

3) Students want the school to provide students self-learning ability courses.

S: guide students to self-learning courses is the beginning of progress

S: a course that can help students think logically, perhaps in a similar way to topic analysis

\section{CONCLUSIONS}

The features and innovation of this study is that it combines the CDIO-based curriculum, creativity and problem solving to develop "CDIO-based creative problem-solving scale." To sum up, the conclusions can be summarized as follows.

1) Students feel positive toward the CDIO-based curriculum design. In this generation, teachers have to change to meet the students' need, so does the curriculum. The traditional "teacher-centered" instruction need to be revised, and the "student-centered" approach need to be applied into the class. In the past, teachers may worry about students' ability to complete the real projects. However, through the CDIO-based courses, students can learn from the hands-on activities. In addition, they work with their peers instead of working on the project alone. Working in the team gives them opportunities to communicate with one another, and the positive attitude really influence students' learning to be more active.

2) According to the results, students' feel their creativity and problem-solving abilities have been increased. Through the CDIO-based courses, students learn that more than one answer is possible. Since it is "student-centered," they are allowed to use their imagination to find solutions. Besides, they are not afraid of facing challenging questions, and they are excited about problem-solving process.

In this study, the participants are from the construction and engineering colleges who form interdisciplinary teams and take interdisciplinary required courses. In the future, more hands-on activities can be added and adapted to any curriculum. Moreover, interdisciplinary courses and learning can be applied to other fields, such as business, education or science.

\section{REFERENCES}

[1] M. H. Nassir and C. H. Chong, "CDIO attainment for Taylor's undergraduate chemical engineering programme," Taylor's $7^{\text {th }}$ Teaching and Learning Conference 2014 Proceedings, pp. 235-245, 2014.

[2] C. E. Hmelo-Silver, "Problem-based learning: What and how do students learn?" Educational Psychology Review, vol. 16, no. 3, pp. 235-266, September 2004.

[3] L. Pittaway and J. Cope, "Simulating entrepreneurial learning: Integrating experiential and collaborative approaches to learning," Management Learning, vol. 38, no. 2, pp.211-233, 2007.

[4] R. M. Felder and R. Brent, "Understanding student differences," Journal of Engineering Education, vol. 94, no. 1, pp. 57-72, 2005.

[5] E. F. Crawley, J. Malmqvist, S. Östlund, and D. R. Brodeur, Rethinking Engineering Education, $2^{\text {nd }}$ ed. Springer Singapore: Springer.

[6] M. Li, "Applying the CDIO engineering education standards to optimize services provided by subject librarians," World Transactions 
on Engineering and Technology Education, vol. 12, no. 4, pp. 623-627, 2014.

[7] C. Chen and Z. Zhu, "Reform in engineering education based on the concept of CDIO education," Education and Modernization, vol. 3, no. 1, pp. 30-33, 2010.

[8] A. Ayob, A. Hussain, and R. A. Majid, "A review of research on creative teachers in higher education," International Educational Studies, vol. 6, no. 6, pp. 8-14, 2013.

[9] H. Gardner, Five Minds for the Future, Harvard: Harvard Business School, 2007.

[10] H. Gibson, "What creativity isn't: The presumptions of instrumental and individual justifications for creativity in education," British Journal of Education Studies, vol. 53, no. 2, pp. 148-167, 2005.

[11] D. Dunne and R. Martin, "Design thinking and how it will change management education: an interview and discussion," Academy of Management Learning \& Education, vol. 5, no. 4, pp. 512-523, 2006.

[12] H. Platner. (2010). An Introduction to Design Thinking Process Guide. [Online]. pp. 1-6. Available: https://dschool.stanford.edu

[13] C. L. Dym, A. M. Agogino, O. Eris, D. D. Frey, and L. J. Leifer, "Engineering design thinking, teaching, and learning," Journal of Engineering Education, pp. 103-120, January, 2005.

[14] C. M. Christensen, The Innovator's Dilemma, New York: Harper Business Essentials, 2003.

[15] M. Alexander, The Imagination Challenge, Berkeley, CA: New Riders, 2007.

[16] J. Lee, "Experiences of intensive English learners: Motivations, imagined communities, and identities," English Language Teaching, vol. 7, no. 11, pp. 28-38, 2014.

[17] D. H. Lim and H. Kim, "Motivation and learner characteristics affecting online learning and learning application," Journal of Educational Technology Systems, vol. 31, no. 4, pp. 423-439, 2003.

[18] R. M. Ryan and E. L. Deci, "Intrinsic and extrinsic motivations: Classic definitions and new directions," Contemporary Educational Psychology, vol. 25, pp. 54-67, 2000.

[19] R. Benabou, "Intrinsic and extrinsic motivation," Review of Economic Studies, vol. 70, pp. 489-520, 2003

[20] M. J. Prince, and R. M. Felder, "Inductive teaching and learning methods: definitions, comparisons, and research bases," Journal of Engineering Education, vol. 95, no. 2, pp. 123-138, 2006.

[21] D. Jonassen, "Supporting problem solving in PBL," Interdisciplinary Journal of Problem-Based Learning, vol. 5, no. 2, pp. 95-119, 2011.

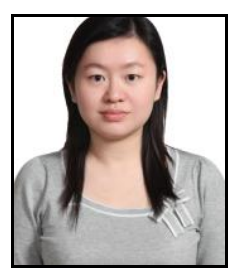

Bor-Tyng Wang is currently an associate professor of Foreign Language Center at Feng-Chia University, Taiwan. She received her Ph. D. degree in Graduate Institute of Educational Measurement and Statistics from National Taichung University of Education, Taiwan. She likes to apply teaching theories to the practical teaching and enjoys trying to teach in innovative ways. Her research interests include English language teaching, language assessment and call.

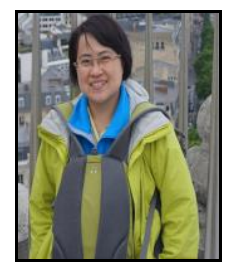

Ching-Yi Lee is currently a post-doctoral fellow in the Center for Teaching and Learning Resource at Feng Chia University. She is also an adjunct assistan professor who teaches creative thinking and design thinking. Dr. Lee current research focuses on engineering education, structural equation modelling, imagination, vocational training and higher education.

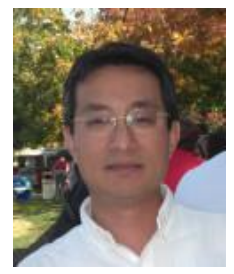

Chuang-Chien Chiu is a distinguished professor of the Department of Automatic Control Engineering as well as the Vice President of Feng Chia University, Taichung, Taiwan. His previous experiences include the dean of the Center for General Education, the dean of Academic Affairs, the dean of the College of Information and Electrical Engineering, and the chair of the Department of Automatic Control Engineering, all at Feng Chia University. His research interests include ambulatory monitoring with wearable technology (smart shirt), biomedical signal processing and neural networks, with particular emphasis on physiological signal analysis for autonomic nervous system, speech analysis, image processing, and developing real-time medical system for tongue diagnosis and objective auscultation in traditional Chinese medicine.

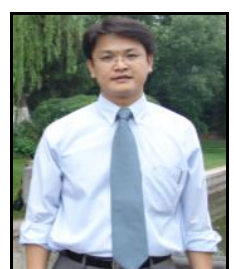

Chun-Wen Teng is currently an associate professor of Graduate Institute of Public Policy at Feng-Chia University, Taiwan. He received his $\mathrm{Ph}$. D. degree in the Department of Education from National Chengchi University, Taiwan. His research interests include higher education, curriculum and instruction design and e-learning. He was also the executive officer of Center for Teaching and Learning Resource at Feng-Chia University. 